\title{
Mechanical and thermal properties of crab chitin reinforced carboxylated SBR composites
}

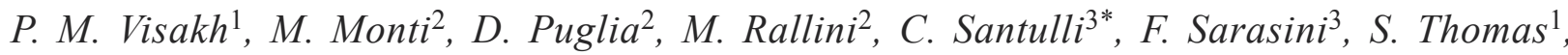 \\ J. M. Kenny ${ }^{2}$ \\ ${ }^{1}$ Centre for Nanoscience and Nanotechnology, Mahatma Gandhi University Kottayam, Kerala, India \\ ${ }^{2}$ University of Perugia, UdR INSTM, Department of Civil and Environmental Engineering, Strada di Pentima 4, 05100 \\ Terni, Italy \\ ${ }^{3}$ Department of Chemical Engineering Materials Environment, Sapienza-Universita di Roma, Via Eudossiana 18, 00184 \\ Roma, Italy
}

Received 18 September 2011; accepted in revised form 1 December 2011

\begin{abstract}
The addition of small amounts (up to $9 \mathrm{wt} \%$ ) of chitin microsized particles, originating from shellfish waste, to carboxylated styrene-butadiene rubber (XSBR) matrix (as received and annealed to $100^{\circ} \mathrm{C}$ ) has been studied. In particular, this study concentrated on their mechanical (creep investigation by nanoindentation and dynamical-mechanical analysis), thermal (differential scanning calorimetry and thermogravimetry) and swelling behaviour (toluene absorption) and was completed by morphological characterisation by scanning electron microscopy and atomic force microscopy.

The results show that annealing has a limited effect on materials properties, effects which are further reduced by the addition of growing amounts of crab chitin. It should be noted that the limited filler content used in the study does not substantially modify the linear creep behaviour of XSBR for sufficiently long loading times. The thermal stability of the system does also appear to be preserved even with the maximum chitin content added, while it serves sufficiently as an effective barrier against aromatic solvent absorption.
\end{abstract}

Keywords: rubber, nanoidentation, crab chitin, thermal properties, solvent absorption

\section{Introduction}

Chitin is a high molecular weight polymer, mainly with linear structure, based on a polysaccharide compound containing an acetamide group, specifically $\beta$-(1 to 4$)$ ( $\mathrm{N}$-acetyl -D-glucosamine). It is widely present in plants and animals, being the second most abundant biopolymer in nature after cellulose and therefore biodegradable: in addition to being biodegradable, chitin is highly crystalline and depending on its origin it occurs in three forms identified as $\alpha, \beta$, and $\chi$ chitin [1]. Other positive qualities include non-toxicity, non-allergenicity, anti-microbial effect, insolubility in water and resistance to acids, alkalis, and many organic solvents, ver- satile biological activity and excellent biocompatibility [2]. The above characteristics make chitin suitable for applications in a number of areas other than food industry, such as e.g., in biosensors, and in medical and pharmaceutical applications as wound-dressing material and device for controlled drug release [3].

Chitin can easily be isolated from crab shell, when it is found to be highly thixotropic and liquid crystalline [4]. When isolating the crystalline regions of chitin, referred to as whiskers, from the crab shells and squid pens by hydrochloric acid hydrolysis, it was found that these microfibrillar arrangements have quite uniform properties [5]. In the specific

\footnotetext{
${ }^{*}$ Corresponding author, e-mail: carlo.santulli@uniroma1.it
} (c) BME-PT 
case of chitin whiskers extracted from crab shells, the distribution in length has been found to range from 100 to $500 \mathrm{~nm}$, while diameter was between 10 and $80 \mathrm{~nm}$, which implied that the average aspect ratio (length/diameter), was $10 \pm 5$ [6].

The introduction of these natural polymers as nanofillers in a rubber matrix has been suggested, to improve specific properties in some applications. In particular, they are likely to reduce the amount of swelling due to absorption in membranes [7], and can allow SBR to compete with vulcanised rubber, in that their reinforcing capability, depending on the aspect ratio of the chitin, can be comparable to the traditional inorganic nanofillers e.g., clay [8]. In addition, the compatibilization efficiency of styrenebutadiene matrices generally depends on the conditions of blend preparation and processing [9]. In particular, thermal annealing of rubber blends results often in a substantial hardening of the material, which is capable of providing a stronger interface for the possible introduction of reinforcement in the rubbery matrix [10].

If suitable conditions for compatibility are achieved, the active surface of natural nanofillers facilitates chemical derivation and grafting, and forms strong physical interaction with polymer matrix. This was explained by the fact that the whiskers take the appearance of a rigid network, which results from strong interactions between them, in particular from hydrogen bonds: the network is possibly governed by a percolation mechanism only at high temperature [11]. Unmodified chitin whiskers, obtained from squid pen [12] and crab shells [5] have been tested as the reinforcing elements in polymer matrices, such as polycaprolactone [13], acrylic resins [14] and natural rubber [4-6]. Modification of chitin whiskers by different chemical agents, in particular succinic anhydride, and different types of isocyanates, has also been attempted, with no substantial improvement for the introduction into a natural rubber matrix [15]. It has been suggested that this loss of performance is due to the partial destruction of the aforementioned three-dimensional network of chitin whiskers assumed to be present in the unmodified composites [16].

This work concentrates on the study of the mechanical and thermal properties of composites with crab chitin introduced into an XSBR latex: a number of studies of these properties for the pure unvulcan- ized matrix are available, in particular [9, 17-20]. This study does also include the degradation scenario of these composites, in particular measuring their dynamical properties, their creep profile, their temperature degradation and their swelling by toluene absorption.

\section{Materials and methods}

\subsection{Materials}

\subsubsection{Base materials}

The XSBR latex used in this study was supplied by Apar Industries Ltd., Bombay, Maharashtra, India. Table 1 reports the most important features of this latex. $\alpha$-Chitin powder was supplied by Marine Chemicals, Cochin, Kerala, India. All the chemical products needed for the chitin treatments, namely $3 \mathrm{~N}$-hydrochloric acid $(\mathrm{HCl})$, potassium hydroxide ( $\mathrm{KOH}-5 \%$ solution), sodium hypochlorite $\left(\mathrm{NaClO}_{2}\right)$ (solution for bleaching) and $3 \mathrm{~N}$-sodium acetate buffer, were purchased by Indian chemical suppliers. In order to obtain nano-sized chitin whiskers, a process consisting in several steps was carried out.

Table 1. Properties of carboxylated styrene butadiene rubber latex

\begin{tabular}{|l|l|}
\hline Dry rubber content (DRC) & $47 \%$ \\
\hline Total solid content (TSC) & $50.7 \%$ \\
\hline Styrene content & $59 \%$ \\
\hline $\mathrm{pH}$ & 8.60 \\
\hline Mechanical stability & Good \\
\hline
\end{tabular}

\subsubsection{Chitin deproteinisation}

The first part of the process consists in the deproteinisation of the chitin. Firstly, the chitin powder was stirred and boiled with $5 \mathrm{wt} \%$ aqueous $\mathrm{KOH}$ solution for $6 \mathrm{~h}$. Then it was rinsed with distilled water and filtered. Lamarque et al. [21] reported that the sodium hydroxide concentration influences the nanostructure of chitin whiskers. After this treatment, chitin was bleached with $17 \mathrm{~g}$ of $\mathrm{NaClO}_{2}$ in $1 \mathrm{~L}$ of distilled water mixed with $27 \mathrm{~g}$ of $\mathrm{NaOH}$ in $75 \mathrm{~mL}$ of acetic acid completed with $925 \mathrm{~mL}$ of distilled water. The suspension was stirred at $80^{\circ} \mathrm{C}$ for $2 \mathrm{~h}$. This procedure was repeated three times.

\subsubsection{Preparation of nanochitin whiskers}

The chitin whisker suspensions were prepared by hydrolyzing the purified chitin with $3 \mathrm{~N} \mathrm{HCl}$ at the boiling point for $1.5 \mathrm{~h}$ while stirred. After acid 
hydrolysis the suspensions were dialyzed for $2 \mathrm{~h}$ in distilled water and then overnight in running water. An additional dialysis by dialysis bag for $12 \mathrm{~h}$ by changing the distilled water every $2 \mathrm{~h}$ was performed until a $\mathrm{pH}=6$ was reached. The dispersion of whiskers was completed by three successive ultrasonic treatments for 2 minutes each. The concentration of the chitin particles suspension was $2.88 \mathrm{~g}$ over the $40 \mathrm{~mL}$ batches, which means $7.2 \mathrm{wt} \%$, then it was progressively diluted to obtain the other concentrations.

\subsubsection{Preparation of composites}

In order to obtain the blends, the XSBR latex and the chitin suspension were mixed together and stirred for 2 hours, then cast in Petri dishes. The solid nanocomposite films were obtained drying the solution in an oven at $40^{\circ} \mathrm{C}$, allowing the water to evaporate.

In all the prepared composites, the XSBR latex volume fraction was kept constant, whereas the volume fraction of chitin whiskers suspension was tuned from 30 to $70 \mathrm{vol} \%$, which correspond to a weight between 2.16 and 5.04 grams of chitin in $100 \mathrm{~mL}$ total XSBR latex. Throughout the present paper, the compositions of the composites are expressed in terms of volume percentages, for convenience. The pure XSBR matrix is also prepared and used as the control. To observe the effect of an annealing treatment on the produced materials, the neat XSBR and all the nanocomposite blends were heated to $100^{\circ} \mathrm{C}$ for 90 minutes, then tested and compared with the non-annealed ('as received') materials. This procedure has the aim of showing the effect of exposure to a temperature slightly exceeding the maximum service temperature, in particular showing the effect of high temperature washing (vapour vacuum cleaning) on the material, thinking of the below mentioned application of it in the textile field.

The annealing treatment can be supposed to yield an accelerated drying of the composites, also from water collected by chitin, given that lower temperatures, usually 40 or $60^{\circ} \mathrm{C}$, have been applied for that purpose in literature [22-23] and also harden the rubber matrix by removing the water content of the latex. Heating at this temperature is also likely to promote filler flocculation, as proposed in [24], to modify their geometry and evaluate the effect of this treatment on the mechanical properties. The flocculation effect for the filler has been revealed for equivalent systems in [9], demonstrating that even the addition of a few weight percent of synthesized clays, up to $2.5 \%$ of unmodified fluorohectorite, produces a slight but perceivable decrease of the viscosity.

Table 2 summarized all the studied materials with their composition.

\subsection{Methods}

\subsubsection{DMA analysis}

Dynamical mechanical analysis has been often performed on filled systems based on including unvulcanised rubber to determine the viscoelastic properties of the system $[5,17,25,26]$. In this work, DMA was performed by using a Rheometric Scientific (Piscataway, NJ, USA) -ARES N2 rheometer. The sample size was $10 \mathrm{~mm}$ in width, $30 \mathrm{~mm}$ in length, and about $1.5 \mathrm{~mm}$ in thickness. The measurements were carried out in the dynamic time sweep test starting from $T=-40$ up to $80^{\circ} \mathrm{C}$ (heating rate $=$ $5^{\circ} \mathrm{C} / \mathrm{min}$ ) and frequency fixed at $1 \mathrm{~Hz}$ and shear strain at $0.15 \%$. The storage modulus, loss modulus and loss factor $(\tan \delta)$ of the samples were measured.

\subsubsection{SEM analysis}

An assessment on the morphological aspects of the produced material was carried out with a field emission scanning electron microscope (FESEM) ZEISS (Carl Zeiss s.p.a., Arese, Italy) model Supra 25.

\subsubsection{AFM examination}

The chitin whiskers, as well as the nanocomposites, were also characterized using a Veeco (Plainview,

Table 2. Composition of the different samples used

\begin{tabular}{|c|c|c|c|c|}
\hline XSBR latex [mL] & Chitin solution $[\mathbf{m L}]$ & Chitin content $[\mathbf{g}]$ & Chitin $\mathbf{w t} \%$ & Samples \\
\hline 100 & 0 & 0 & 0 & XSBR, XSBR-A \\
\hline 100 & 30 & 2.16 & 4.1 & CW30, CW30-A \\
\hline 100 & 50 & 3.60 & 6.6 & CW50, CW50-A \\
\hline 100 & 70 & 5.04 & 9.0 & CW70, CW70-A \\
\hline
\end{tabular}

Samples marked with A have been annealed at $100^{\circ} \mathrm{C}$ 
NY, USA) MultiMode scanning probe microscope with a Nanoscope $\mathrm{V}$ controller. For the analysis of chitin, a droplet of the aqueous whisker suspension ( $0.5 \%$ by weight $)$ was dried on a mica surface prior to AFM examination. The nanocomposite films were microtomed using a diamond knife after embedding in epoxy resin and were analyzed directly. The images for the whiskers and the nanocomposites were collected using a tapping mode etched silicon tip, with a nominal spring constant of $5 \mathrm{~N} / \mathrm{m}$ and a nominal frequency of $270 \mathrm{kHz}$.

\subsubsection{Thermogravimetric analysis (TGA)}

The thermal stability of the produced materials was investigated by means of thermogravimetric analysis (TGA). The measurements were performed with a thermogravimetric analyzer Seiko (Seiko Instruments, Inc., Chiba, Japan) model Exstar 6300 in nitrogen atmosphere, and consisted in dynamic scans at the heating rate of $20^{\circ} \mathrm{C} / \mathrm{min}$ from 30 to $900^{\circ} \mathrm{C}$. Bulk samples of about $(10 \pm 1) \mathrm{mg}$ were tested.

\subsubsection{Differential scanning calorimetry (DSC)}

Differential scanning calorimetry was performed using a differential scanning calorimeter MDSC TA (TA Instruments, Vimodrone, Italy) model Q200. The temperature range analyzed was -90 to $200^{\circ} \mathrm{C}$.

\subsubsection{Swelling experiments}

Toluene absorption tests on as-received and annealed samples have also been carried out, with the idea of considering the durability of the matrix and its envisaged application, which was discussed above.
The kinetics of toluene absorption was determined for XSBR based composites. The specimens used were square shaped samples with $2 \mathrm{~mm}$ side and around $1-1.5 \mathrm{~mm}$ thick. The thickness, $2 L$, of the film was therefore supposed to be thin enough so that the molecular diffusion was considered to be one-dimensional. After weighing, the samples were immersed in toluene. The samples were removed at specific intervals $(t)$ and weighed $\left(M_{\mathrm{t}}\right)$ up to an equilibrium value $\left(M_{\infty}\right)$. The swelling rate of the samples was calculated by dividing the gain in weight $\left(M_{\mathrm{t}}-M_{0}\right)$ by the initial weight $\left(M_{0}\right)$. Since these swelling experiments were more difficult to perform for unvulcanized materials (part of the sample could dissolve in toluene), the following analysis was also performed for these samples. Thin square shaped samples were first weighed $\left(M_{0}\right)$ and then immersed in toluene for $48 \mathrm{~h}$. They were subsequently dried for $12 \mathrm{~h}$ at $55-60^{\circ} \mathrm{C}$ and weighed again $\left(M_{0^{\prime}}\right)$. The 'sol' fraction $\left(M_{0^{\prime}} / M_{0}\right)$ and relative weight loss (RWL) $\left[M_{0}-M_{0^{\prime}}\right] / M_{0}$ were then determined. This allowed estimating the fraction of XSBR bonded to the filler and the fraction of XSBR dissolved in toluene.

\subsubsection{Nanoindentation creep testing}

A NanoTest nanoindenter, supplied by MicroMaterials Inc. (Tampa, FL, USA), was employed to study the creep behaviour of the produced materials. This equipment consists of a pendulum-based depth sensing system, with the sample vertically mounted. A Berkovich-type three-sided pyramidal indenter was used. The indentation was load-controlled to $0.05 \mathrm{mN}$ maximum load for $200 \mathrm{~s}$ as the holding period. All

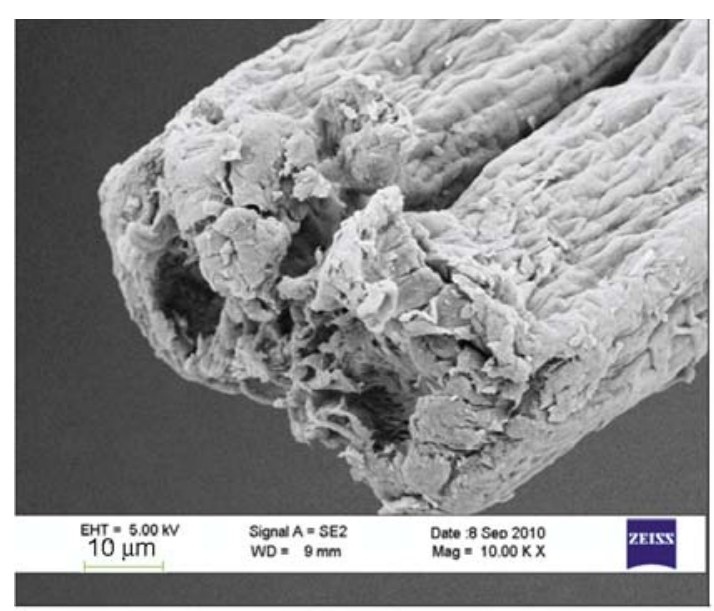

a)

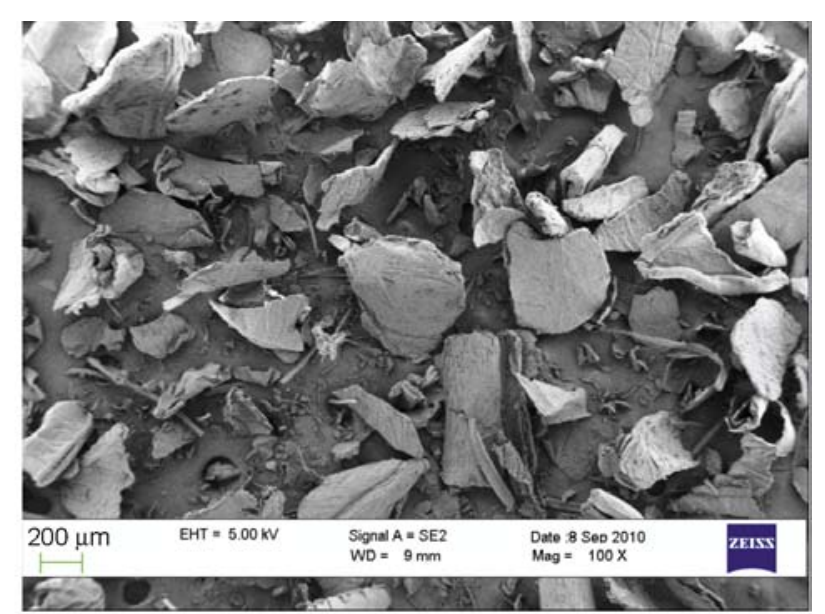

b)

Figure 1. (a) Tip of a chitin whisker, (b) general appearance of chitin powder 
the tests were performed at $23^{\circ} \mathrm{C}$. Twenty tests were performed on each sample, in order to obtain a good reliability of the results.

\section{Results}

Commercial chitin from crab shells consists of a mixture of roughly spherical particles with diameter around $0.5-1 \mathrm{~mm}$ and ill-defined particles [4]. The treatment followed generated intertwined and spiralling chitin microfibrils, forming whiskers such as the one whose tip is reproduced in Figure 1a. However, the general appearance of chitin powder still includes a wide variability of particle geometries and sizes, as illustrated in Figure $1 \mathrm{~b}$.

The discussion of results obtained focused on the two effects of the addition of an increased quantity of crab chitin in the matrix and of XSBR rubber annealing. Crab chitin addition allowed using a waste product originating from seafood industries, while the matrix was annealed to prepare it to the envisaged use of XSBR as back coating for textiles and carpets, for which application an increased resistance to wear and to degradation due e.g., to solvent absorption, is desirable. Previous studies suggested that the addition of limited amounts of chitosan to natural rubber latex decreases benzene diffusivity, an effect which is likely to be observed also in this case for small amounts of chitin [24].

The four-element Burgers model has been used to approximate the creep behaviour in solid-filled rubber [27] and more recently also in natural fibre reinforced polymers $[28,29]$. This model is commonly represented by the simultaneous presence of two

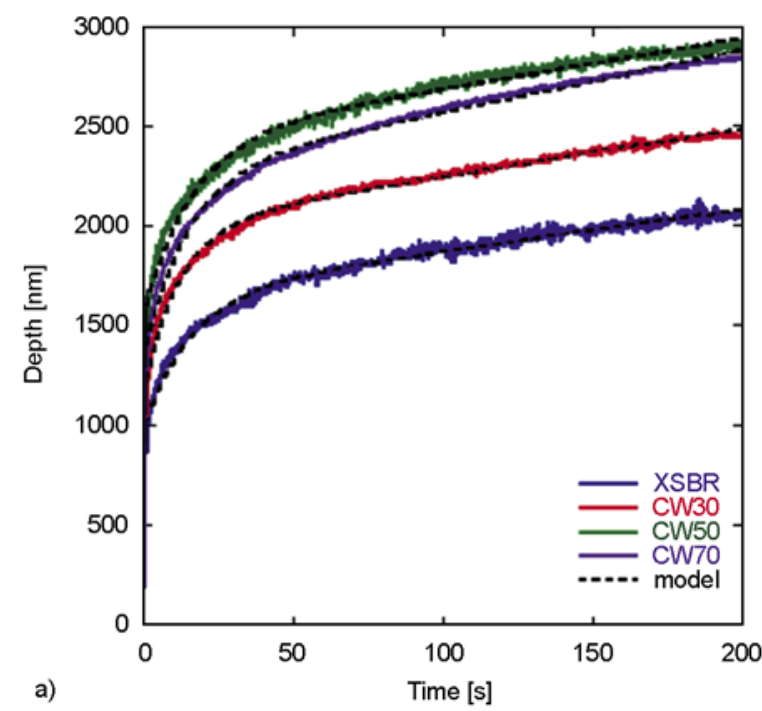

Table 3. Constants obtained from the creep model

\begin{tabular}{|l|c|c|c|c|}
\hline \multicolumn{1}{|c|}{ Samples } & $\mathbf{K}_{\mathbf{1}}[\mathbf{N} / \mathbf{m}]$ & $\mathbf{K}_{\mathbf{2}}[\mathbf{N} / \mathbf{m}]$ & $\boldsymbol{\eta}_{\mathbf{1}}[\mathbf{N} \cdot \mathbf{s} / \mathbf{m}]$ & $\boldsymbol{\eta}_{\mathbf{2}}[\mathbf{N} \cdot \mathbf{s} / \mathbf{m}]$ \\
\hline XSBR & 48.664 & 80.901 & 1279.90 & 23104 \\
\hline XSBR-A & 38.028 & 64.658 & 925.33 & 16152 \\
\hline CW30 & 40.979 & 65.195 & 773.15 & 20113 \\
\hline CW30-A & 31.537 & 70.305 & 1154.00 & 22019 \\
\hline CW50 & 31.279 & 60.763 & 985.45 & 19678 \\
\hline CW50-A & 53.239 & 103.150 & 1535.60 & 24940 \\
\hline CW70 & 35.733 & 58.925 & 857.38 & 16083 \\
\hline CW70-A & 78.949 & 188.090 & 1981.00 & 41791 \\
\hline
\end{tabular}

elastic constants (springs): elastic recovery $\left(K_{1}\right)$ and rubbery elasticity $\left(K_{2}\right)$, and two viscous constants (dashpots): molecular 'slip' $\left(\eta_{1}\right)$ and delayed elasticity $\left(\eta_{2}\right)$. Respective values are reported in Table 3.

The model appears to closely match the experimental results of creep tests by nano-indentation (Figure 2), giving a representation as the function $H(t)=A \cdot \ln (B \cdot \mathrm{t}+1)$. Comparing the creep results between the as-received and annealed samples, annealing results in a highly increased resistance to indentation for the samples with higher chitin content (CW50 and CW70), an effect which is not observed for the pure XSBR and the CW30 sample. This is a perceivable trend, although the bulk values provided by nanoindentation are not directly comparable with the calculation of elastic modulus. This is due to the fact that it provides information on hardness and surface profile of modulus, surface-based information whose application to the material in general can be affected by the non uniformity of the matrix and further aggravated by the presence of the filler. As a general point, it can be suggested that filler flocculation is amongst the

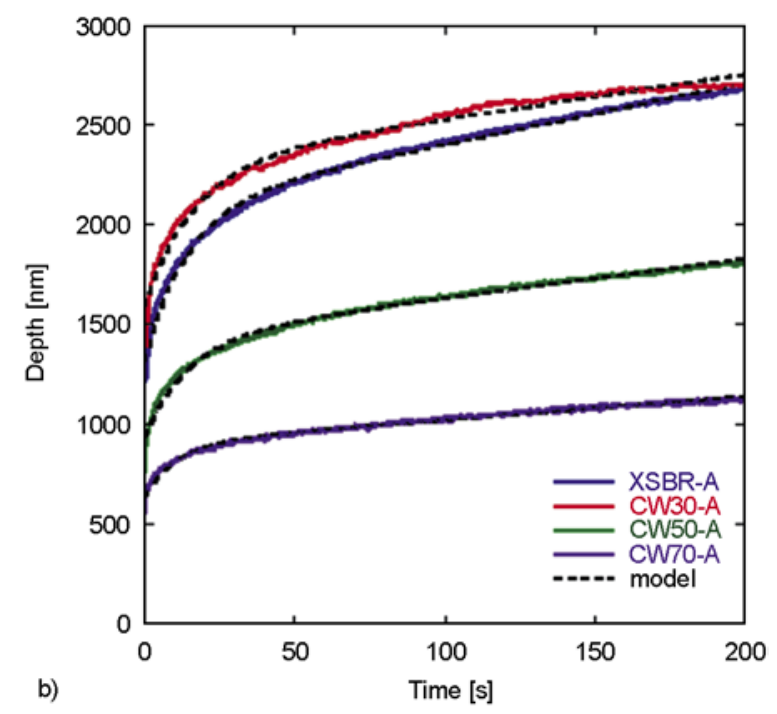

Figure 2. Nano-indentation curves for normal (a) and annealed samples (b) 
Table 4. Comparison of the rigidity of normal and annealed samples

\begin{tabular}{|l|r|r|r|r|}
\hline \multirow{2}{*}{ Compared samples } & \multicolumn{4}{|c|}{ Depth difference after } \\
\cline { 2 - 5 } & $\begin{array}{c}\mathbf{5 0 ~ s} \\
{[\mathbf{n m}]}\end{array}$ & $\begin{array}{r}\mathbf{1 0 0} \text { s } \\
{[\mathbf{n m}]}\end{array}$ & $\begin{array}{r}\mathbf{1 5 0} \text { s } \\
{[\mathbf{n m}]}\end{array}$ & $\begin{array}{r}\mathbf{2 0 0} \text { s } \\
{[\mathbf{n m}]}\end{array}$ \\
\hline XSBR-A vs. XSBR & 580 & 650 & 630 & 640 \\
\hline CW30-A vs. CW30 & 270 & 250 & 320 & 230 \\
\hline CW50-A vs. CW50 & -980 & -1100 & -1120 & -1080 \\
\hline CW70-A vs. CW70 & -1450 & -1480 & -1690 & -1770 \\
\hline
\end{tabular}

Table 5. DMA variables for the different samples

\begin{tabular}{|l|c|c|c|}
\hline \multicolumn{1}{|c|}{ Material } & $\mathbf{T}_{\text {peak }}\left[{ }^{\circ} \mathrm{C}\right]$ & $\tan \boldsymbol{\delta}$ & $\boldsymbol{\Delta}_{\mathbf{0 . 5 p e a k}}\left[{ }^{\circ} \mathrm{C}\right]$ \\
\hline XSBR & -6.32 & 1.15 & 17.48 \\
\hline XSBR-30CW & -5.63 & 0.78 & 25.07 \\
\hline XSBR-50CW & -9.26 & 0.81 & 19.54 \\
\hline XSBR-70CW & -7.96 & 0.97 & 18.44 \\
\hline XSBRA & -8.26 & 1.20 & 16.24 \\
\hline XSBR-30CWA & -7.57 & 0.95 & 19.09 \\
\hline XSBR-50CWA & -9.07 & 1.08 & 17.81 \\
\hline XSBR-70CWA & -8.21 & 0.78 & 20.45 \\
\hline
\end{tabular}

Table 6. Storage and loss moduli for the different samples at $25^{\circ} \mathrm{C}$

\begin{tabular}{|l|c|c|}
\hline \multicolumn{1}{|c|}{ Material } & $\mathbf{G}^{\prime}[\mathbf{P a}]$ at $\mathbf{2 5}^{\circ} \mathbf{C}$ & $\mathbf{G}^{\prime \prime}[\mathbf{P a}]$ at 25${ }^{\circ} \mathbf{C}$ \\
\hline XSBR & $1.3905 \cdot 10^{6}$ & $1.8260 \cdot 10^{5}$ \\
\hline XSBRA & $1.4405 \cdot 10^{6}$ & $1.4695 \cdot 10^{5}$ \\
\hline XSBR-CW30 & $3.9459 \cdot 10^{6}$ & $1.0366 \cdot 10^{6}$ \\
\hline XSBR-CW30A & $3.9459 \cdot 10^{6}$ & $7.0493 \cdot 10^{5}$ \\
\hline XSBR-CW50 & $8.8983 \cdot 10^{6}$ & $3.0748 \cdot 10^{6}$ \\
\hline XSBR-CW50A & $6.2482 \cdot 10^{6}$ & $1.1311 \cdot 10^{6}$ \\
\hline XSBR-CW70 & $1.7701 \cdot 10^{7}$ & $1.6984 \cdot 10^{6}$ \\
\hline XSBR-CW70A & $2.5251 \cdot 10^{7}$ & $3.9928 \cdot 10^{6}$ \\
\hline
\end{tabular}

Table 7. Values of glass transition temperature for the different samples

\begin{tabular}{|l|c|}
\hline \multicolumn{1}{|c|}{ Material } & $\left.\mathbf{T}_{\mathbf{g}}{ }^{\circ}{ }^{\circ} \mathbf{C}\right]$ of XSBR from DSC analysis \\
\hline XSBR & 10.0 \\
\hline XSBR_A & 13.8 \\
\hline CW30 & 14.2 \\
\hline CW30_A & 13.3 \\
\hline CW50 & 12.2 \\
\hline CW50_A & 14.6 \\
\hline CW70 & 16.0 \\
\hline CW70_A & 16.7 \\
\hline
\end{tabular}

causes of increased resistance to indentation provided by the annealed, therefore temperature-aged, samples [30].

By subtracting the depth of nano-indentation at times between 50 and 200 seconds between the asreceived and the corresponding annealed sample, the results reported in Table 4 are obtained, which further clarify the trend observed above. In particular, the rubber matrix does not appear to depart from linearity for high times of loading, as it would have probably be the case for higher filler contents [31]. In addition, annealing at temperatures exceeding the XSBR critical temperature (glass transition of the styrene phase) does result in an easier cracking of the matrix after annealing (Figure 3), an effect which appears mitigated nevertheless by the introduction of progressively growing amounts of crab chitin.

The DMA results (reported in Figure 4 and Table 5) confirm that, as expected, the increasing content of filler in the polymeric matrix has the effect of rising the $G^{\prime}$ modulus in the entire temperature range. The tan delta values for the different systems are almost the same, confirming the calorimetric observations. The amplitude in terms of $\Delta T$ of the tan delta peak at the half of the maximum value, indicated as $\Delta T_{0.5}$ (reported in the last column of Table 5) slightly grows, even with the introduction of the lowest quantity of chitin.

The annealing treatment has a weak effect on the loss modulus profile, in the sense that only a small increase of the $G^{\prime}$ values is obtained in the entire temperature range due to the resulting stiffening. For comparison, the storage and loss modulus values measured at $T=25^{\circ} \mathrm{C}$ are reported in Table 6 .

DSC results, reported in Table 7, demonstrate that glass transition temperature $T_{\mathrm{g}}$ has a slight growth with increasing chitin content, and some less perceivable increase is also observed as an effect of annealing, which was justified by matrix stiffening. The calorimetric results suggest that the annealing at $100^{\circ} \mathrm{C}$ maintained for 90 minutes does only slightly modify the mobility of the polymer chains, even in presence of chitin nanoparticles.

TGA and DTG measurements (Figures 5 and 6) demonstrate that chitin addition does not substantially change the thermal stability of XSBR matrix: in other words, the annealing process does not have a large influence on the maximum weight loss rate. The presence of the degradation peak of the chitin is visible in the DTG profile as a shoulder of the main peak at $360-375^{\circ} \mathrm{C}$ (depending on the filler content), while the peak due to the matrix degradation remains virtually unchanged. These results confirmed that the thermal stability of the system is 


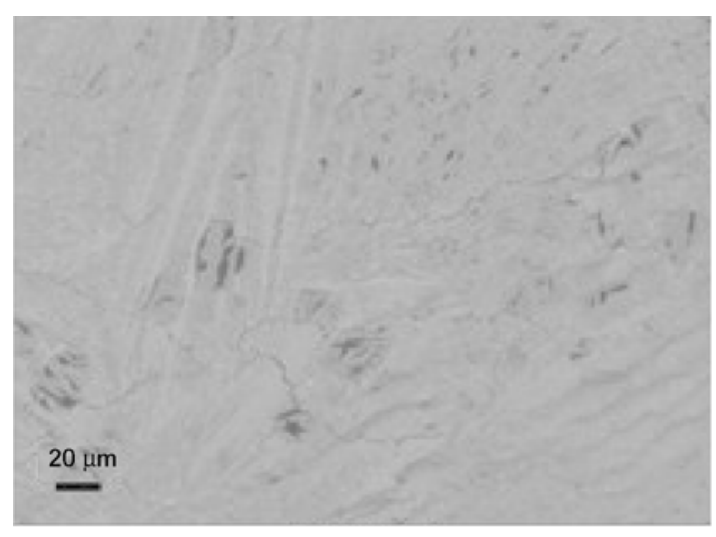

\section{XSBR}

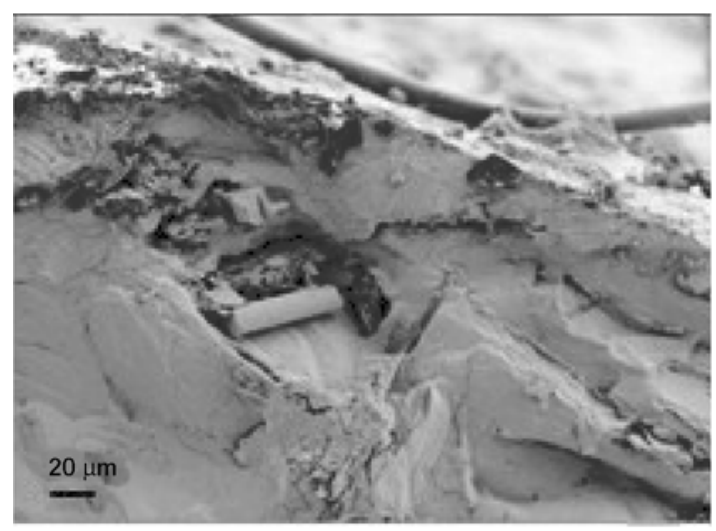

CW30

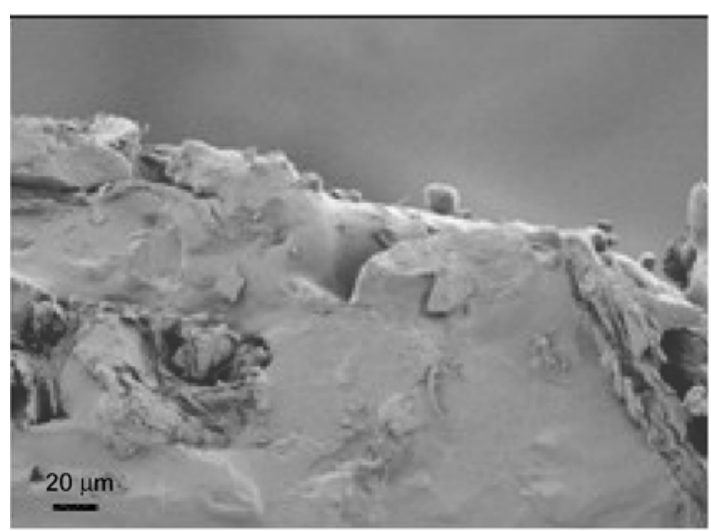

CW50

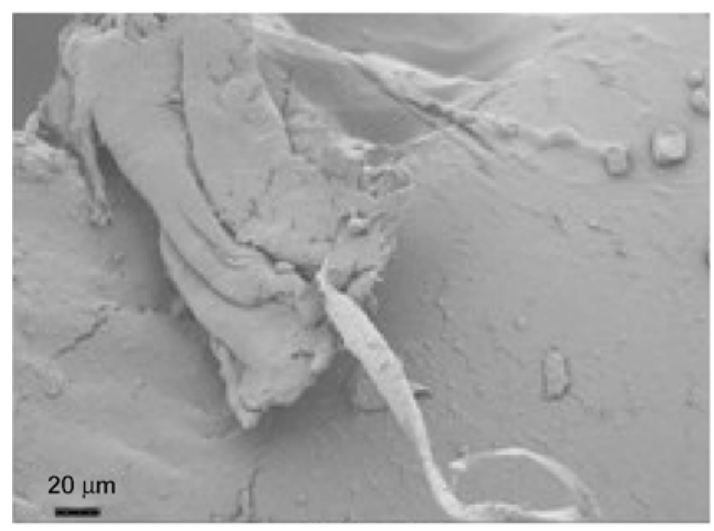

CW70

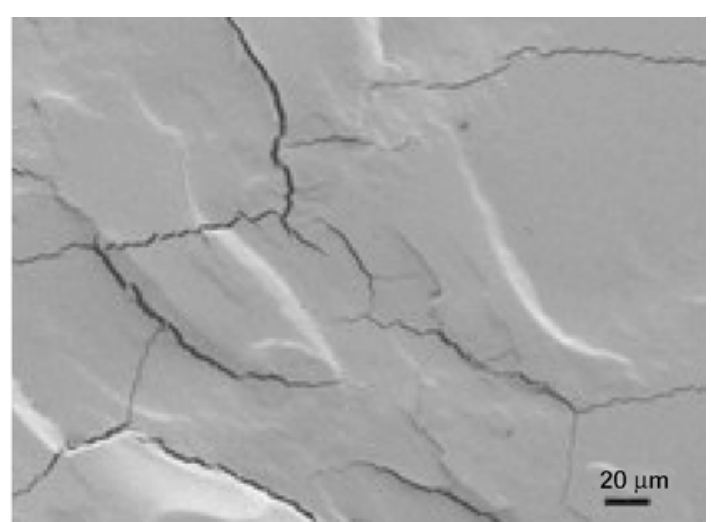

XSBR_A

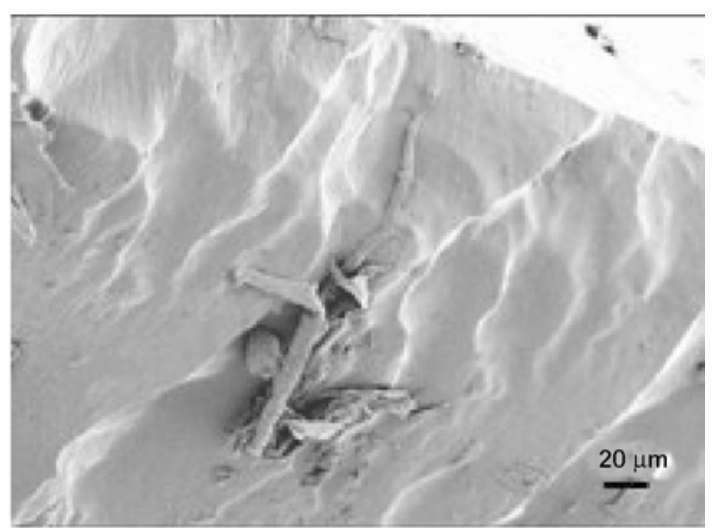

CW30_A

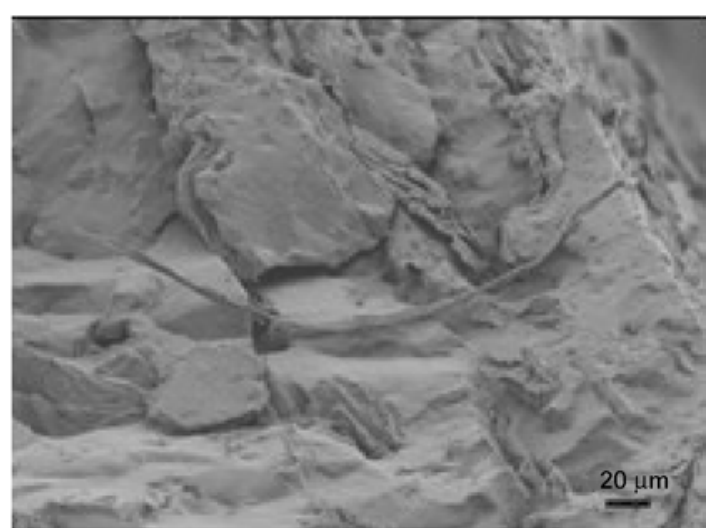

CW50_A

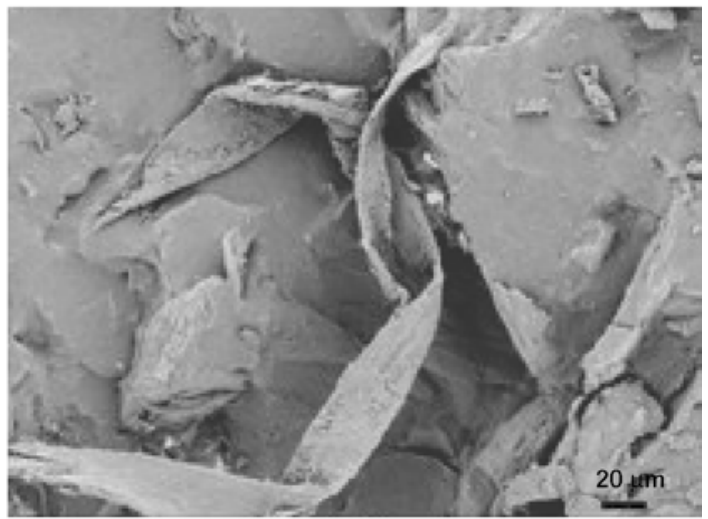

CW70_A

Figure 3. Comparison between as received (left) and annealed (right) SBR nanocomposites 


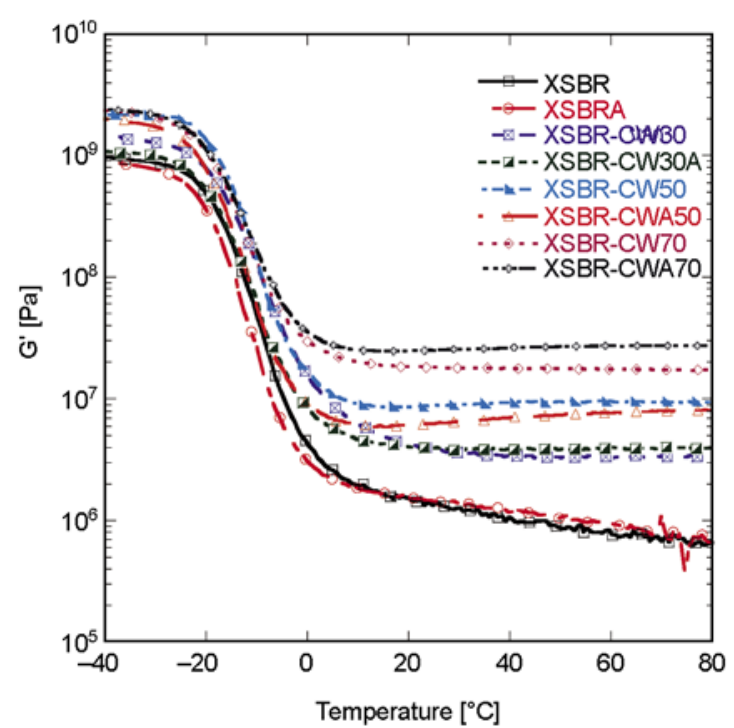

Figure 4. Storage modulus of the different samples

preserved, also with variable amounts of natural filler with thermally unstable behaviour. This can be considered as a positive outcome, since it demonstrated that the introduction of a natural filler, which is inherently thermally unstable, does not cause at these concentrations any change in the thermal stability of XSBR rubber.

Toluene absorption tests on as-received and annealed samples have also been carried out, with the idea of considering the durability of the matrix and its final application, which was discussed above. The selection of the solvent was done considering the matrix and its final application, not the filler The sorption tests (Figure 7) demonstrate that the maximum weight gain is obtained for the unfilled XSBR matrix, while the decreasing slope in the curve

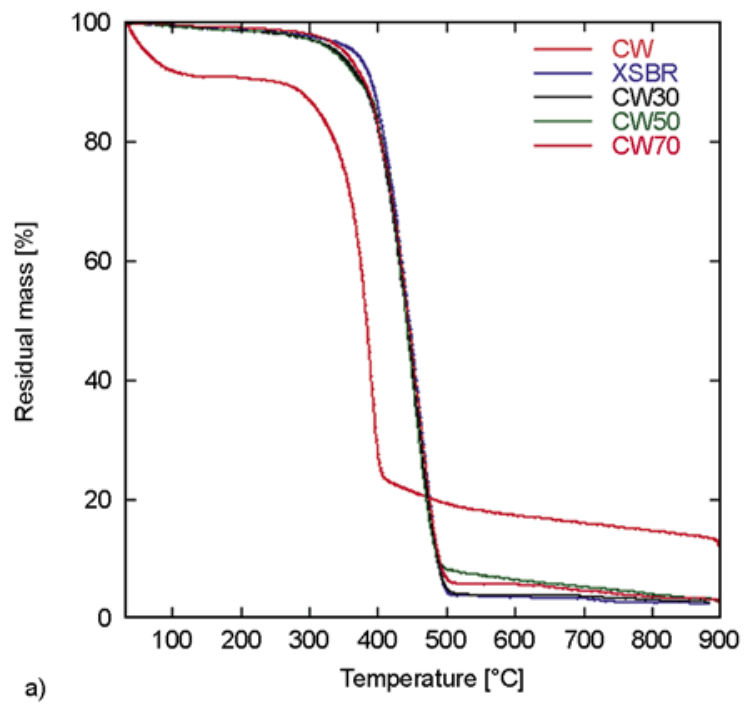

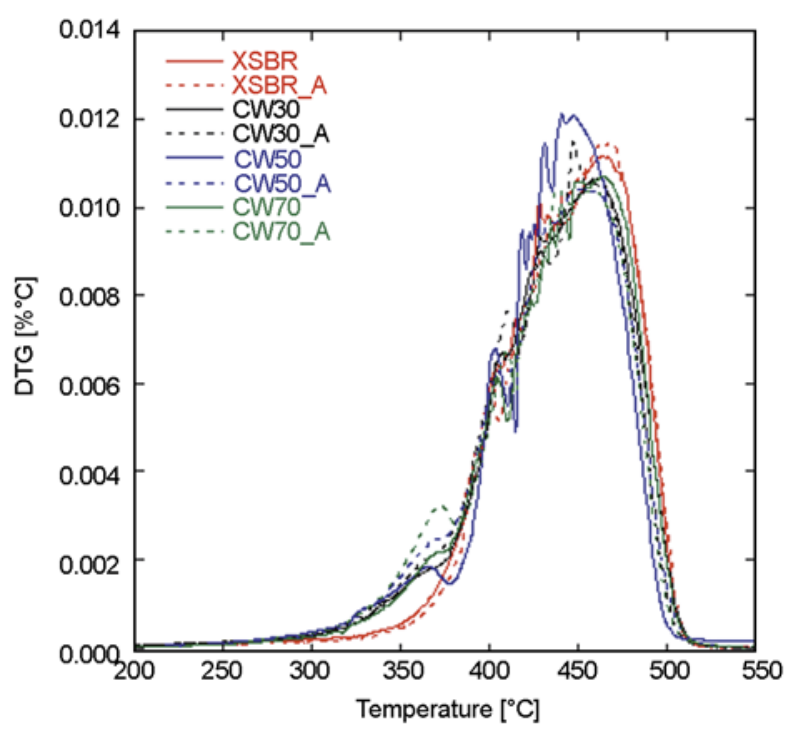

Figure 6. DTG of as-received and annealed samples

(weight gain $v s$ time $^{1 / 2}$ ) is an indication of the effectiveness of the chitin as a barrier to the solvent uptake. In general, it has been shown already as XSBR samples filled with clay or silica micronsized fillers showed reduced swelling rate owing to the tortuosity of the path [32].

The same result can be observed in experiment limited at 48 hours, point at which the systems start to lose their shape and going into solution due to the unvulcanized state of the rubber: the scattering of the different curves in Figure 7a is due to this condition. In particular, toluene absorption is decreased with growing chitin content in rubber. The larger effect is observed for the addition of the first $30 \%$. The effect of annealing on this property appears to be not very consistent, apart from $70 \%$ samples,

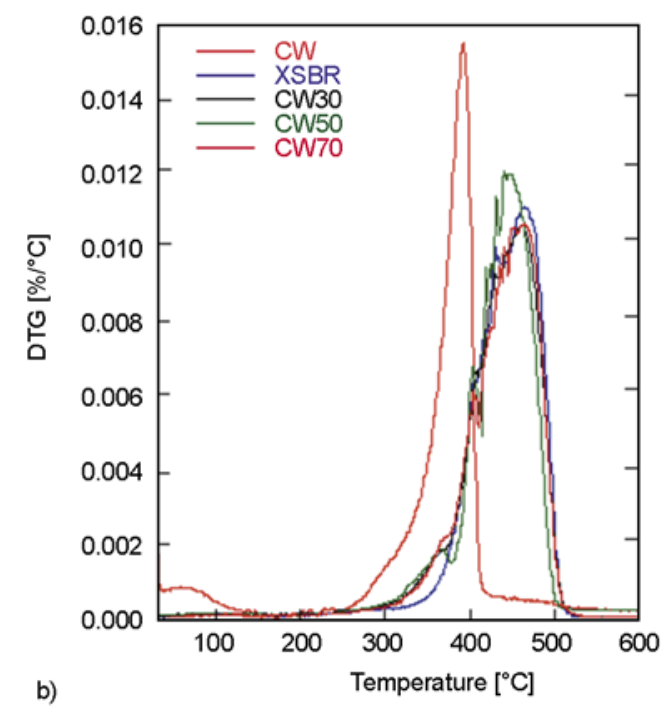

Figure 5. TGA and DTG results of as-received samples, compared with results from pure chitin (CW) 


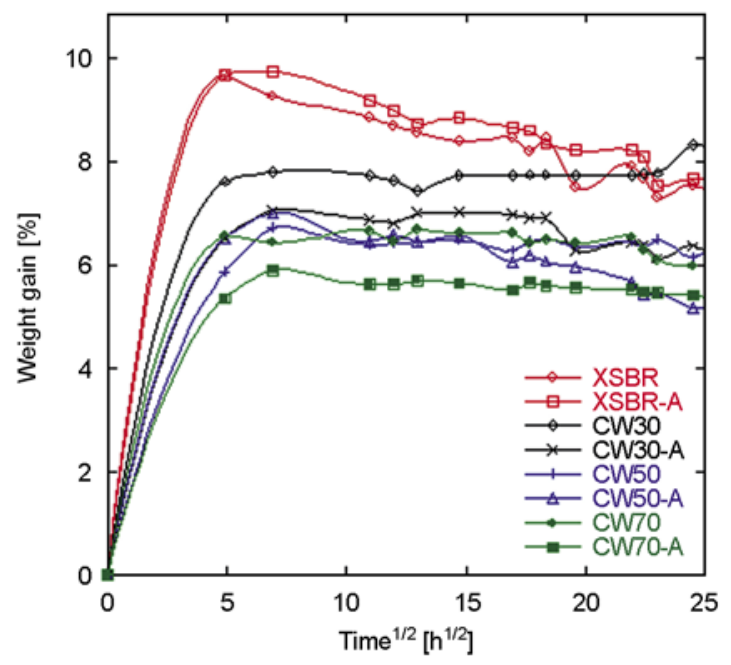

a)

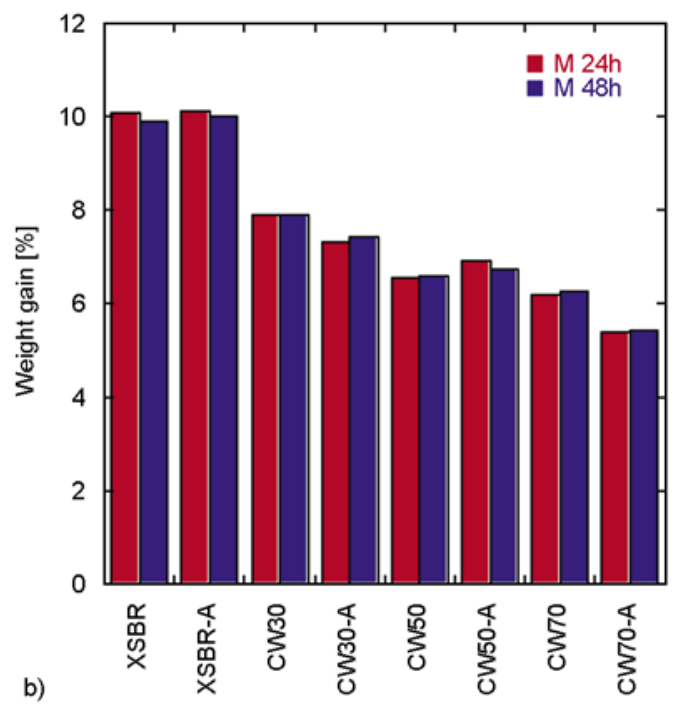

Figure 7. Weight gain during toluene absorption for 600 hours (a) and details of the comparison of 24 and 48 hours (b)

\begin{tabular}{|c|c|c|c|c|c|}
\hline Measurement time & M0 & M48 & Measurement time & M0 & $\begin{array}{l}48 \\
\end{array}$ \\
\hline XSBR57 & 2 & & XSBR_A & 8 & \\
\hline cW30 & 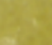 & 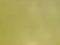 & CW30_A & e & 8 \\
\hline CW50 & & 1 & CW50_A & & 1 \\
\hline CW70 & & & CW70_A & & \\
\hline
\end{tabular}

Figure 8. Aspect of samples before and after toluene absorption for 48 hours

where it may be due to reduced mobility of chitin filler, which does not allow allocating more solvent in the material. It is also noteworthy that the annealing does not ease geometry preservation during degradation due to toluene absorption (Figure 8). The morphological investigation of the samples by SEM (Figures 9 and 10) highlighted that the solvent absorption gives rise to an exfoliation of the rubber matrix, showing the weak interface between the XSBR and aggregates of chitin nanowhiskers, which have micrometric dimensions. This effect is not substantially worsened by the annealing treat- ment (Figure 10), a finding that suggests once again that exposure to $100^{\circ} \mathrm{C}$ temperature for limited amounts of time does not significantly modify the properties of the material.

The observation of the chitin powder with the nanowhiskers was possible under AFM: this showed clearly the typical needle-like structure of the whiskers (Figure 11a) [33], while these are disposed non uniformly across the matrix (Figure $11 \mathrm{~b}$ ), a finding which may explain the aforementioned interface issues. 

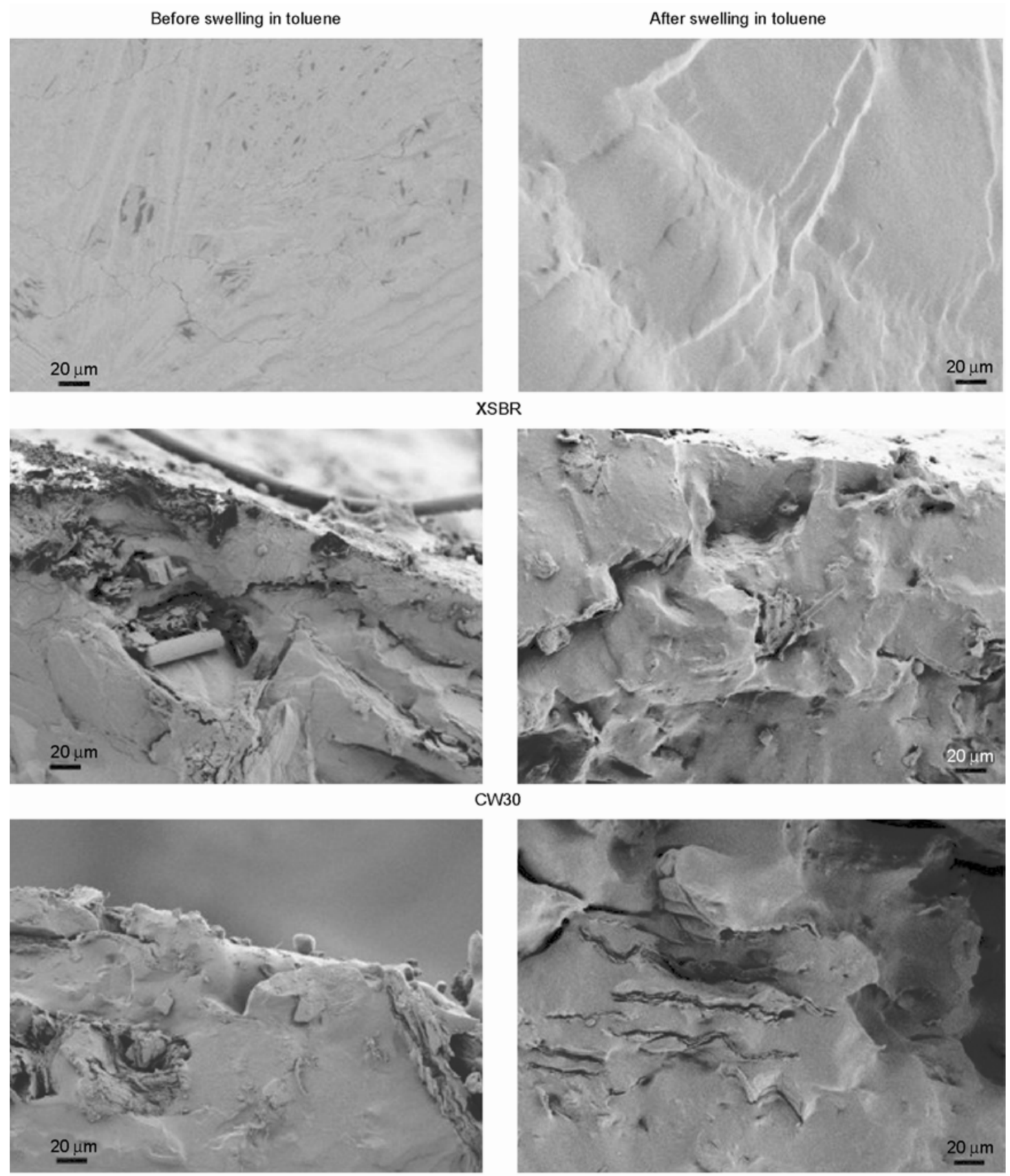

CW50
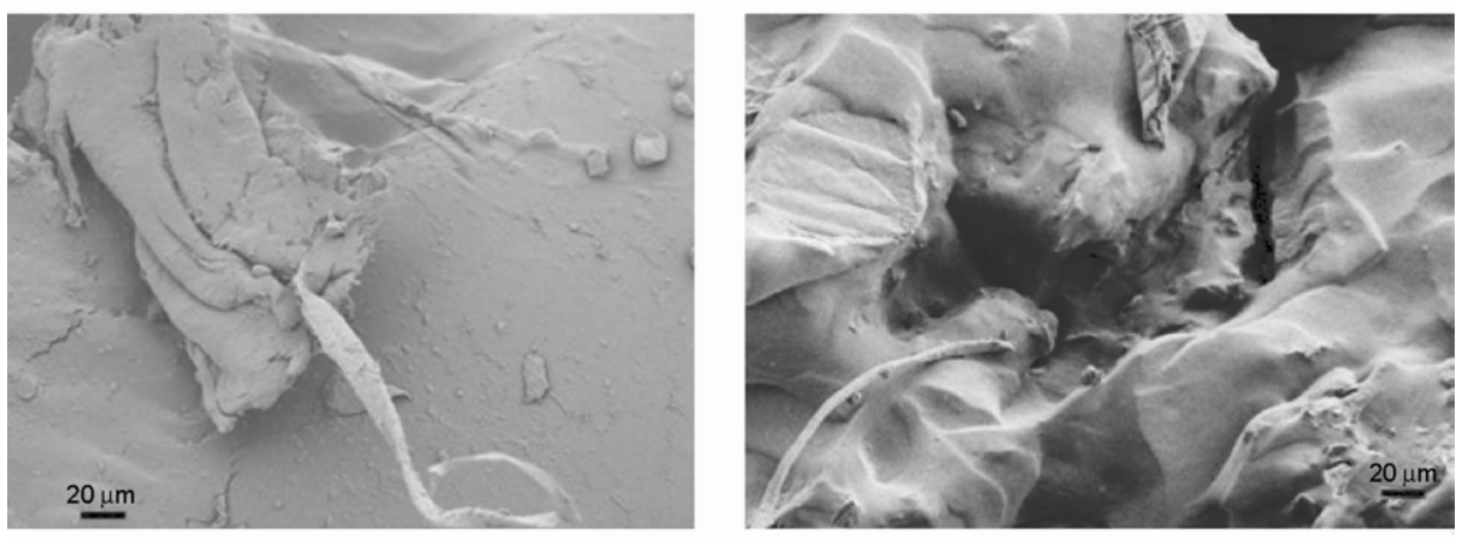

CW70

Figure 9. SEM micrographs of samples as received before and after toluene absorption for 48 hours 

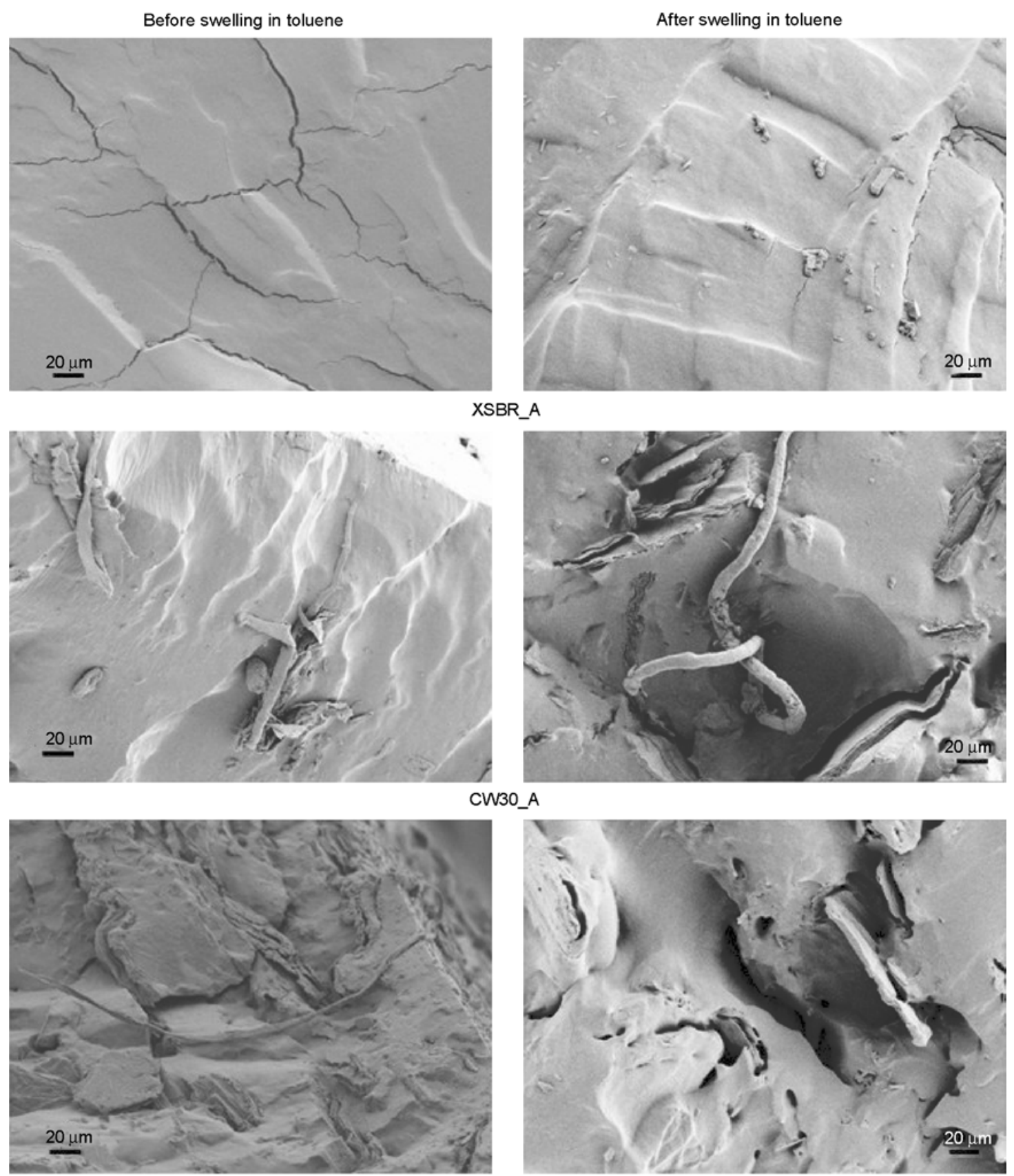

CW50_A
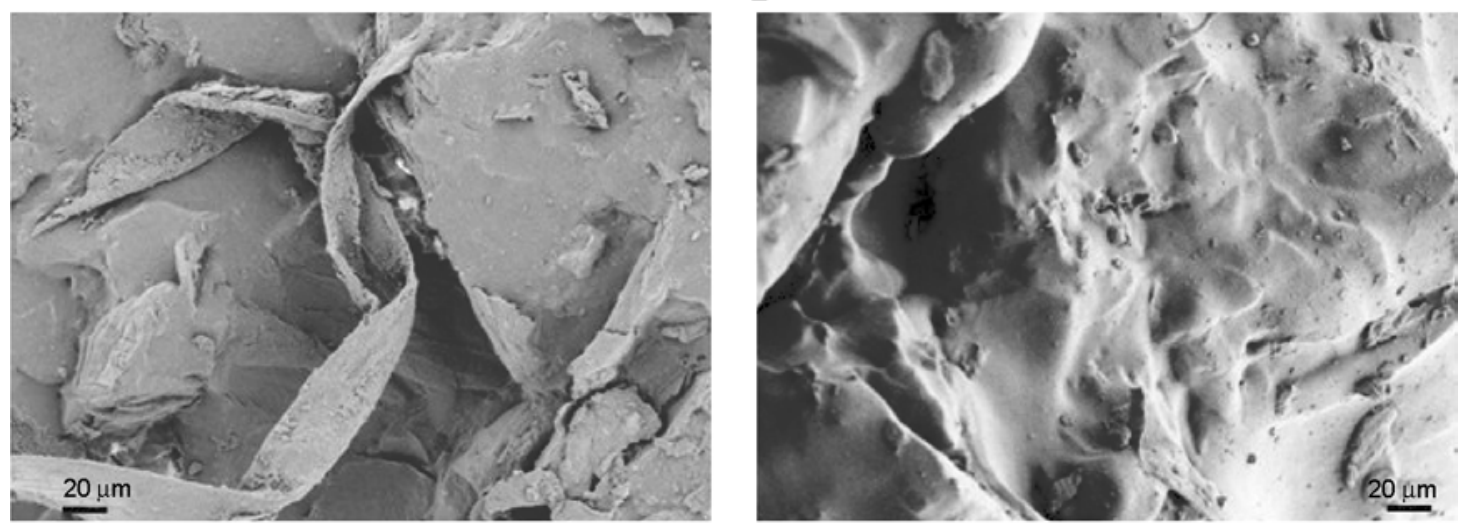

CW70_A

Figure 10. SEM micrographs of annealed samples before and after toluene absorption for 48 hours 

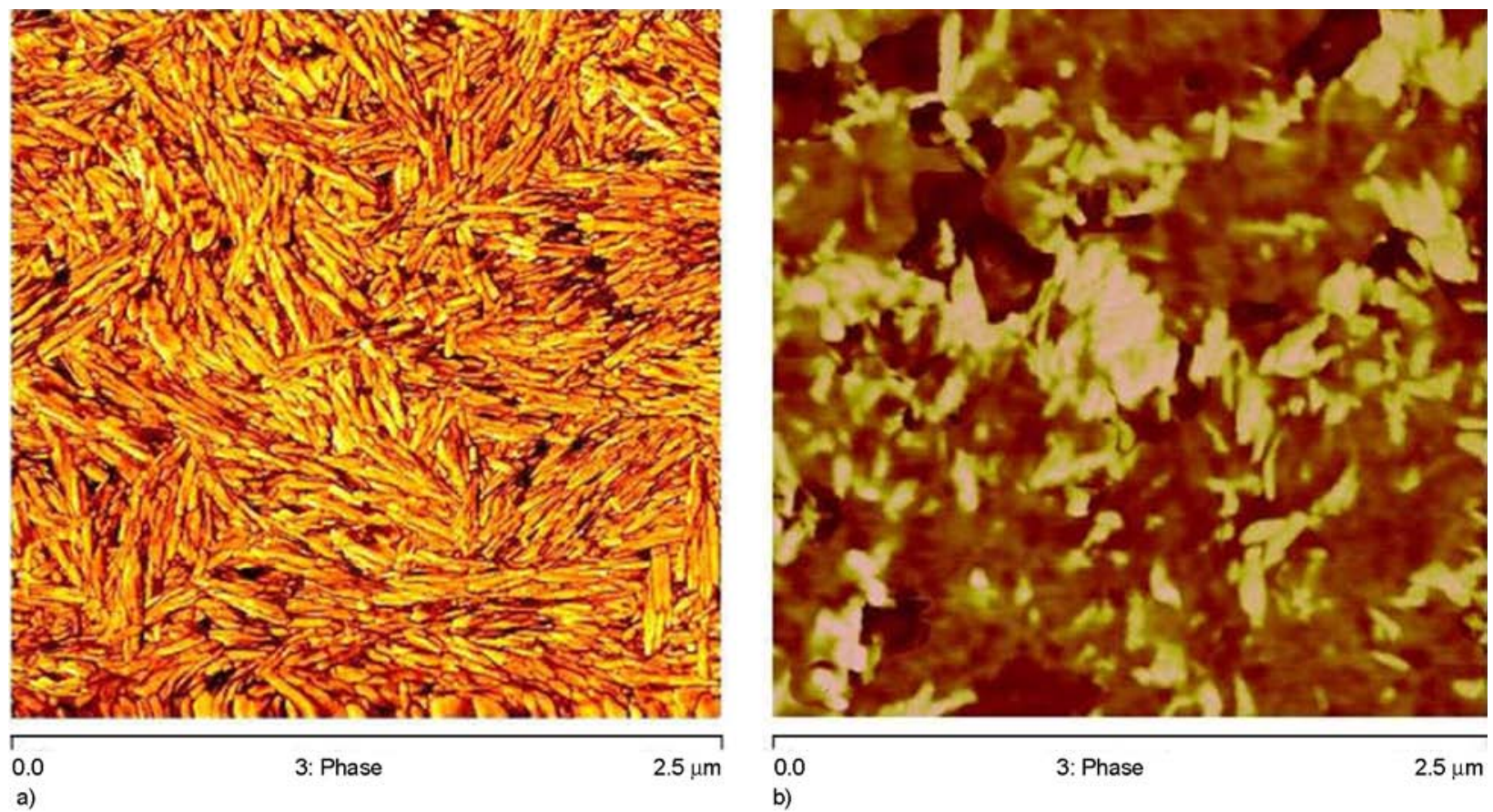

Figure 11. AFM imaging of: (a) a dilute suspension of nanochitin whiskers and (b) XSBR-CW50 (6.6 wt $\%$ chitin whisker nanocomposites)

\section{Conclusions}

This investigation was mainly aimed at evaluating the effect of the addition of small quantities of crab chitin from shellfish waste on the thermal, mechanical and morphological properties and swelling behaviour under toluene absorption of carboxylated styrene-butadiene rubber. A subsequent objective was also measuring the variation of the above properties as a consequence of annealing to $100^{\circ} \mathrm{C}$, to give indication of the system resistance to service in the envisaged application (back coating for textiles and carpets).

The results show that crab chitin, also in very low amounts, offers some solvent barrier effect, while on the other side it does not substantially affect the thermal stability and the creep properties of the matrix. In addition, the system does not appear to be substantially modified by the exposure at high temperature for limited amounts of time, compatible with service needs (annealing was applied for 90 minutes).

This study can be suggestive for the investigation of the effect of introduction of different microsized fillers, originating from waste products, in this rubber matrix or in other similar blends.

\section{References}

[1] Dufresne A.: Natural rubber green nanocomposites. in 'Rubber nanocomposites: Preparation, properties, and applications' (eds.: Thomas S., Stephen R.) Wiley, Singapore, 113-146 (2010). DOI: $10.1002 / 9780470823477 . c h 5$

[2] Wang Z., Hu Q., Cai L.: Chitin fiber and chitosan 3D composite rods. International Journal of Polymer Science, 2010, 369759/1-369759/7 (2010).

DOI: $10.1155 / 2010 / 369759$

[3] Chen L., Du Y., Wu H., Xiao L.: Relationship between molecular structure and moisture-retention ability of carboxymethyl chitin and chitosan. Journal of Applied Polymer Science, 83, 1233-1241 (2002).

DOI: $10.1002 / a p p .2290$

[4] Nair K. G., Dufresne A.: Crab shell chitin whisker reinforced natural rubber nanocomposites. 1. Processing and swelling behavior. Biomacromolecules, 4, 657665 (2003).

DOI: $10.1021 / \mathrm{bm} 020127 \mathrm{~b}$

[5] Nair K. G., Dufresne A.: Crab shell chitin whisker reinforced natural rubber nanocomposites. 2. Mechanical behavior. Biomacromolecules, 4, 666-674 (2003). DOI: 10.1021/bm0201284

[6] Visakh P. M., Thomas S.: Preparation of bionanomaterials and their polymer nanocomposites from waste and biomass. Waste and Biomass Valorisation, 1, 121134 (2010). DOI: $10.1007 / \mathrm{s} 12649-010-9009-7$ 
[7] Stephen R., Varghese S., Joseph K., Oommen Z., Thomas S.: Diffusion and transport through nanocomposites of natural rubber (NR), carboxylated styrene butadiene rubber (XSBR) and their blends. Journal of Membrane Science, 282, 162-170 (2006).

DOI: $10.1016 /$ j.memsci.2006.05.019

[8] Shams M. I., Ifuku S., Nogi M., Oku T., Yano H.: Fabrication of optically transparent chitin nanocomposites. Applied Physics A: Materials Science and Processing, 102, 325-331 (2010).

DOI: $10.1007 / \mathrm{s} 00339-010-5969-5$

[9] Stephen R., Alex R., Cherian T., Varghese S., Joseph K., Thomas S.: Rheological behavior of nanocomposites of natural rubber and carboxylated styrene butadiene rubber latices and their blends. Journal of Applied Polymer Science, 101, 2355-2362 (2006).

DOI: $10.1002 /$ app. 23852

[10] Soares B. G., Cario F. O. Jr.: Reactive compatibilization of polystyrene/poly(ethylene-co-vinyl acetate) (EVA) blends. Journal of Applied Polymer Science, 99, 14-22 (2006).

DOI: $10.1002 / a p p .21856$

[11] Junkasem J., Rujiravanit R., Grady B. P., Supaphola P.: $\mathrm{X}$-ray diffraction and dynamic mechanical analyses of $\alpha$-chitin whisker-reinforced poly(vinyl alcohol) nanocomposite nanofibers. Polymer International, 59, 8591 (2010).

DOI: $10.1002 /$ pi.2693

[12] Paillet M., Dufresne A.: Chitin whisker reinforced thermoplastic nanocomposites. Macromolecules, 34, 6527-6530 (2001).

DOI: $10.1021 / \mathrm{ma} 002049 \mathrm{v}$

[13] Feng L., Zhou Z., Dufresne A., Huang J., Wei M., An L.: Structure and properties of new thermoforming bionanocomposites based on chitin whisker-graftpolycaprolactone. Journal of Applied Polymer Science, 112, 2830-2837 (2009).

DOI: $10.1002 /$ app.29731

[14] Shams M. I., Ifuku S., Nogi M., Oku T., Yano H.: Fabrication of optically transparent chitin nanocomposites. Applied Physics A: Materials Science and Processing, 102, 325-331 (2010).

DOI: $10.1007 / \mathrm{s} 00339-010-5969-5$

[15] Nair K. G., Dufresne A.: Crab shell chitin whiskers reinforced natural rubber nanocomposites. 3. Effect of chemical modification of chitin whiskers. Biomacromolecules, 4, 1835-1842 (2003). DOI: $10.1021 / \mathrm{bm} 030058 \mathrm{~g}$

[16] Dufresne A.: Processing of polymer nanocomposites reinforced with polysaccharide nanocrystals. Molecules, 15, 4111-4128 (2010).

DOI: $\underline{10.3390 / \text { molecules } 15064111}$
[17] Stephen R., Thomas S., Raju K. V. S. N., Varghese S., Joseph K., Oommen Z.: Dynamic mechanical and dielectric properties of nanocomposites of natural rubber (NR), carboxylated styrene butadiene rubber (XSBR) latices and their blends. Rubber Chemistry and Technology, 80, 672-689 (2007).

DOI: $10.5254 / 1.3548187$

[18] Stephen R., Siddique A. M., Singh F., Kailas L., Jose S., Joseph K., Thomas S.: Thermal degradation and ageing behavior of microcomposites of natural rubber, carboxylated styrene butadiene rubber latices, and their blends. Journal of Applied Polymer Science, 105, 341-351 (2007).

DOI: $10.1002 /$ app. 26042

[19] Stephen R., Raju K. V. S. N., Rao M., Francis B., Joseph K., Thomas S.: Flow properties of unvulcanised natural rubber/carboxylated styrene butadiene rubber latices and their blends. Journal of Applied Polymer Science, 104, 2528-2535 (2006).

DOI: 10.1002/app.25855

[20] Stephen R., Jose S., Joseph K., Thomas S., Oommen Z.: Thermal stability and ageing properties of sulphur and gamma radiation vulcanized natural rubber (NR) and carboxylated styrene butadiene rubber (XSBR) latices and their blends. Polymer Degradation and Stability, 91, 1717-1725 (2006).

DOI: $10.1016 /$ j.polymdegradstab.2005.12.001

[21] Lamarque G., Chaussard G., Domard A.: Thermodynamic aspects of the heterogeneous deacetylation of $\beta$ chitin: Reaction mechanisms. Biomacromolecules, 8 , 1942-1950 (2007).

DOI: $10.1021 / \mathrm{bm} 070021 \mathrm{~m}$

[22] Tomihata K., Ikada Y.: In vitro and in vivo degradation of films of chitin and its deacetylated derivatives. Biomaterials, 18, 567-575 (1997). DOI: $10.1016 / \mathrm{S} 0142-9612(96) 00167-6$

[23] Jang M-K., Kong B-G., Jeong Y-I., Lee C. H., Nah JW.: Physicochemical characterization of $\alpha$-chitin, $\beta$ chitin, and $\gamma$-chitin separated from natural resources. Journal of Polymer Science Part A: Polymer Chemistry, 42, 3423-3432 (2004).

DOI: $10.1002 /$ pola.20176

[24] Johns J., Rao V.: Mechanical properties and swelling behavior of cross-linked natural rubber/chitosan blends. International Journal of Polymer Analysis and Characterization, 14, 508-526 (2009). DOI: $10.1080 / 10236660903072797$

[25] Stephen R., Raju K. V. S. N., Nair S. V., Varghese S., Oommen Z., Thomas S.: Mechanical and viscoelastic behavior of natural rubber and carboxylated styrenebutadiene rubber latex blends. Journal of Applied Polymer Science, 88, 2639-2648 (2003). DOI: $10.1002 /$ app.12012 
[26] Chuayjuljit S., Luecha W.: XSBR/NR rubber blends filled with polystyrene-encapsulated nanosilica prepared by in situ differential microemulsion polymerization. Journal of Elastomers and Plastics, 43, 407427 (2011).

DOI: $10.1177 / 0095244311405001$

[27] Chen C-H., Chen Y-C.: The creep behavior of solidfilled rubber composites. Journal of Polymer Research, 1, 75-83 (1994).

DOI: $10.1007 / \mathrm{BF} 01378597$

[28] Marcovich N. E., Villar M. A.: Thermal and mechanical characterization of linear low-density polyethylene/wood flour composites. Journal of Applied Polymer Science, 90, 2775-2784 (2003).

DOI: 10.1002/app.12934

[29] Nuñez A. J., Marcovich N. E., Aranguren M. I.: Analysis of the creep behavior of polypropylene-woodflour composites. Polymer Engineering and Science, 44, 1594-1603 (2004).

DOI: $10.1002 /$ pen.20157
[30] Bielinski D. M.: Application of microindentation to study ageing of rubber. Kautschuk und Gummi Kunststoffe, 62, 50-54 (2009).

[31] Bohm G. A., Tomaszewski W., Cole W., Hogan T.: Furthering the understanding of the non linear response of filler reinforced elastomers. Polymer, 51, $2057-$ 2068 (2010).

DOI: 10.1016/j.polymer.2010.01.047

[32] Stephen R., Joseph K., Oommen Z., Thomas S.: Molecular transport of aromatic solvents through microcomposites of natural rubber (NR), carboxylated styrene butadiene rubber (XSBR) and their blends. Composites Science and Technology, 67, 1187-1194 (2007). DOI: 10.1016/j.compscitech.2006.05.009

[33] Gupta N. S.: Chitin. Springer, New York (2011). 